\title{
A Framework of Developing a Big Data Platform for Construction Waste Management: A Hong Kong Study
}

\author{
Xi Chen ${ }^{1} *$, Weisheng $\mathrm{Lu}^{2}$, Shiju Liao ${ }^{3}$
}

\begin{abstract}
Big data has shown great potentials in improving management discretion in many areas. The applications of big data in areas such as finance, computer science, health care and medical science have made continued success. Despite of big data's potentials, its applications in construction waste management (CWM) are still in infant stage. In order to embrace these prospects, this research proposes a platform to apply big data technologies in CWM, by focusing on the CWM status of Hong Kong. This study first presents a framework of the big data platform by describing the data collection, storage and analysis involved in the roadmap of CWM in Hong Kong. The existing unintentionally generated big dataset in CWM in Hong Kong is used to examine the availability of the proposed platform. It was found that this platform could make government, industry and other CWM stakeholders benefit from proper cooperation. Though this study focused on the CWM of Hong Kong, it may act as a driving force to stimulate the adoption of big data in CWM across countries where construction waste is growing as an urgent issue that concerns government, industry, academia, and all the stakeholders.
\end{abstract}

Keywords: Construction waste management; Big data; Platform; Hong Kong.

\footnotetext{
${ }^{1 * X i}$ Chen

Department of Real Estate and Construction, The University of Hong Kong, Hong Kong SAR, China chenx90@hku.hk

${ }^{2}$ Weisheng Lu

Department of Real Estate and Construction, The University of Hong Kong, Hong Kong SAR, China

${ }^{3}$ Shiju Liao

School of Construction Management and Real Estate, International Research Centre for Sustainable Built Environment, Chongqing University, China
} 


\section{Introduction}

Construction waste has become a serious problem that hinders the sustainable development worldwide. The U.S. Environmental Protection Agency (EPA) estimated that 136 million tons of building-related construction and demolition (C\&D) debris was generated in 1996 [1]. The wastage rates within the construction industry could reach $10-15 \%$ in UK [2]. In Australia, C\&D waste accounted for a large proportion of the industrial solid waste ended landfills [3]. In Hong Kong, the statistics show that solid waste ending up in landfills reached 14, 311 ton per day (tpd) in 2013, of which $25 \%$ or 3,591 tpd was from construction activities estimated by Hong Kong Environment Protection Department (HKEPD) [4]. Construction waste therefore places tremendous pressure on the valuable landfill space in this highly condensed city. Hong Kong is running out of landfill space far earlier than expected, and the existing landfills will be exhausted one by one by 2020 if waste levels continue to increase at current levels [5]. To pursue construction waste reduction, reuse and recycling (3Rs) researchers in CWM raised measures, such as on-site sorting [6,7], prefabrication [8-10], and selective demolition [11,12]. Innovations are therefore urgently needed to effectively implement the agenda in CWM on the basis of the traditional strategies.

The emerging big data has become a reality with a variety of prospects. Big data is defined as things one can do at a large scale that cannot be done at a smaller one, to create a new form of value in living, working, science and industry by changing markets, organizations, relationship between people, and more [13]. This technology is becoming the frontier for innovation, competition and productivity [14,15]. It has been argued that an organization should foster the data-driven decision-making culture for management revolution to improve management performance [16]. Big data have been proved promising in various disciplines, including medical science [17], ecological science [18] and business [19]. Despite the application success of big data in so many fields, the application of big data in improving the performance of CWM is still in infant stage. Therefore, it is necessary to develop a platform that makes CWM take the advantages of big data technologies.

This research proposes a platform to apply big data technologies in CWM. This paper will present the framework of the big data platform by focusing on the data collection, storage and analysis based on the roadmap of CWM in Hong Kong. The existing unintentionally generated big dataset in CWM and related databases in Hong Kong will be used to examine the availability of the proposed platform.

\section{A Framework of Big Data Platform in CWM}

This study will focus on the collection, storage and analysis of big data in CWM in Hong Kong. First, the CWM roadmap in Hong Kong will be presented to demonstrate the occasions where big data can generate. This study will then describe the framework of big data platform by focusing on the requirements of the basic stages of big data application in CWM, including data collection, storage and analysis.

\subsection{The CWM roadmap in Hong Kong}

Lu and Tam developed a roadmap based on the present CWM status in Hong Kong (see Fig. 1) [20]. This roadmap generally describes the process of transferring construction waste from construction site to government waste reception facilities. In Hong Kong, the waste materials generated on 
construction sites are dealt with 3Rs for using up their value in principle. Then, on-site sorting activities should be conducted to separate 'materials without value' to non-inert and inert waste materials, the rest of which are named mixed construction waste. The three types of waste are sent to corresponding three types of waste reception facilities, namely landfills, public fill reception facilities, and off-site sorting facilities. Within these facilities, the off-site sorting facilities will separate the mixed waste to non-inert and inert materials, which are finally sent to landfills and public reception facilities.

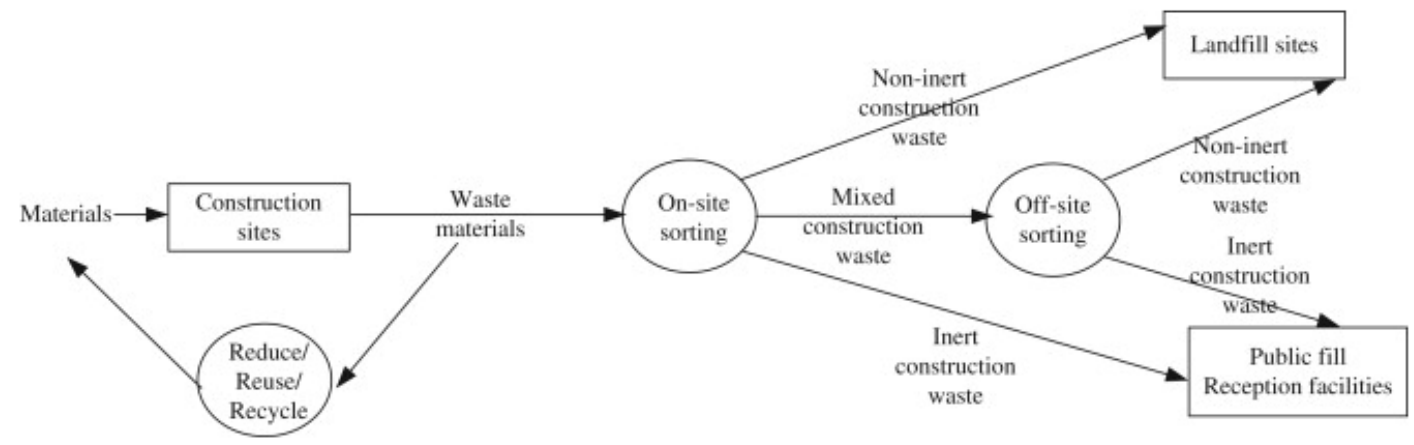

Fig. 1 The roadmap of CWM in Hong Kong developed by Lu and Tam [20]

\subsection{Data collection}

It is much easier to discover patterns in structured data than unstructured data or semi-structured data [21]. The necessary priority for data collection is to establish a scheme, wherein every construction project is demanded to report the project details to an organization at the design, construction, operation and demolition phases. Developers and contractors are clearest on these details, which are suggested fully recorded by government as structured data. Since 2005, Hong Kong Environmental Protection Department has enacted the Construction Waste Disposal Charging Scheme (CWDCS) as legislation to demand contractors open an account number for a construction project, which may send construction waste to disposal facilities managed by government [22]. This scheme recorded information of every construction project with a billing account, which is far from detailed though certain patterns can be discovered from the existing recorded information, including contract sum, site address, department, type of construction work, detail of construction work, and remarks. The good thing is they are formed as structured data filed and stored by EPD, while some information (e.g., floor area of building projects, green building/not green building, developers, building information modeling (BIM) applied/ BIM not applied) useful for analyzing the correlations between CWM and various features has not been recorded in this way. Actually, these details must be available in different organizations, and for unified analysis of data in CWM, they are regarded as unavailable and unstructured data. To address the availability of big data analysis, it is necessary for government to set a well-planed scheme should be set for demanding as much structured data composed of very detailed information contributed by stakeholders as possible to get ready for the future analysis of construction waste.

With the ambition and scheme to collect big data in CWM, the next thing is to define the data 
sources. The roadmap reveals the route of construction waste, where data may generate if sensors are implanted in the right positions. At present, there are some principles to improve CWM performances, so that the proposed platform can conduct data collection with certain purposes. First, the on-site waste 3Rs are crucial for the saving materials [23], thus should be encouraged with incentives. On-site sorting has benefits including increasing the rates of reuse and recycling, reducing the cost for waste transportation and disposal, prolonging the lifespan of landfills designed for receiving non-inert construction waste, and lessening the pollution resulted from the huge amount of construction waste [6,7]. Sensors or manual supervision should be placed to construction site to measure the quantity and types of on-site sorting and materials conducted with 3Rs if a construction project want to apply an award or competition organized by government, such as 'Annual 3Rs Best Award', where CWM performance ranking presents reputation of construction companies. Then, the construction waste is sent to the designated facilities. In the transportation process, the routes and timelines of vehicles may be recorded for analysis for afterward route optimization. The facilities should also record the features of every vehicle of construction waste as structured data for afterward analysis. Also under the CWDCS, EPD have recorded such data since 2005, which is somehow useful but far less than enough to discover much of the value. The data recording should be as systematical and detailed as possible [22]. The data can be collected for real-time and afterward analysis for the purposes that people presently attempt to achieve or are not yet aware of now but might be meaningful someday.

\subsection{Data storage and analysis}

Objects, process and services of the CWM system can generate an explosive growth of many types of new data to be saved and analyzed. This platform needs to find a way forward with its storage infrastructure to facilitate the big data whether it's in the cloud or within the data center. People nowadays are living in a real-time world, therefore the data storage and analysis advance wave upon wave in a very short time period. A power data analytics infrastructure is required to make big data fast, affordable and available for decision makers in some real-time cases. For example, if the routes of vehicles carrying construction waste show that a large number of vehicles are approaching one of the disposal facilities, at that time, the big data platform should inform the other waste haulers who is ready to go to that facility to change their schedule in case of joining a very long queue. Another example is the allocation of vehicles to construction site according to the distances, availability and service attitude of drivers. In this data collection, storage and analysis process, this platform creates transformational value in form of new services, which can be providing convenience to stakeholders in CWM. The nowadays data storage technologies developed by companies, such as IBM have become very mature to deal with the proposed big data generated in CWM in Hong Kong.

The big data generated in the proposed platform are used to discover patterns and correlations using the big data analytics. Big data of waste generation in this study may possibly be used to build models in CWM. Such models (e.g., the waste generation amount vs. construction time model) are very useful in planning the CWM for new projects with proper features input, so that a consultant can make a reasonable waste management plan before the commencement of a new project. With the data growth, the models can be reshaped and more accurate in prediction. These models can also be used to calculate the lifespan of the existing landfills and other facilities, and estimate the 
necessity of building new facilities to facilitate the large amount of construction waste. The value of big data in sustained promotion of CWM can only be realized by hybrid persons who not only have skills in big data technologies, but also know how to tackle problems and communicate with people about these problems, solve them and then figure out the way to transfer the solutions into real scenarios.

\subsection{Stakeholders of the big data platform}

The development of the big data platform aims to bring values to the environment and different groups of people. The most important stakeholders in CWM unavoidably should be government, who manage this platform, and construction companies. Although government has to pay for the establishment of such a platform, the benefits from such a system can be very promising evidenced by the following examples. Stimulating the 3Rs and on-site sorting can reduce the amount of construction waste so as to slow down the environmental deterioration contributed by construction waste. With incentives to stimulate 3Rs on site, the construction companies, which well performed 3Rs, may gain many benefits. The most important benefit is saving cost for materials purchases. On the other hand, Poon et al. suggested that at the first stage, waste producers only need to pay $50 \%$ of the landfilling cost (HK\$ 55/t, US\$ 7/t), but in the subsequent stages, the charge will be increased to cover the full construction and operation costs of the landfill sites [6]. Saving waste disposal cost is another benefit for construction companies. The amount of construction waste received from so many construction sites, the necessity of landfills and other facilities. There are some added benefits for construction companies such as gaining reputation from excellent waste management, followed by more business opportunities. In order to implement the on-site CWM to make sure the availability of the big data platform, government would be better to provide education for contractors, on-site supervision, and easily understanding website with relevant knowledge.

Meanwhile, other stakeholders such as waste haulers, big data professionals, CWM professionals, and residents near landfills may also benefit from this big data platform. For example, this big data platform may provide convenience for construction waste haulers by monitoring their transportation routes. Also, the government can avoid waste illegal dumping activities with haulers under supervision of this real-time tracking system of this platform. The platform may also provide professionals in big data and CWM with career opportunities. People who live in this compact city may worry less about of the building and extension of landfills and other waste disposal facilities near their homes.

\section{Availability of the Big Data Platform in CWM}

Section 2 described a framework of developing the big data platform in CWM. To examine the availability of the platform, this study will raise some examples that can demonstrate big data generated from such a platform have great potential, by analyze the construction waste disposal records recorded by EPD in 2011, 2012, 2013 and 2014 combined with an 'account detail' database. The existing big data are not generated from the proposed big data platform, but would become a part of the big data from the platform once it is established. In the proposed framework, this study 
has raised some potential usages of this platform in providing services and improving environment. Since some of the values are already discovered and published, these studies will be used as examples to demonstrate the availability of this platform.

Chen et al. used more than a million waste disposal records generated in 2011 to benchmark the performance of CWM in Hong Kong [24]. Waste generation rate is a key performance indicator for interpreting the waste management performance. The benchmarks can be used as a baseline for measuring the good or bad performances of CWM. With the benchmarks, the contractors of future projects may constrain their waste generation amount to a reasonable value. Government can also use the benchmarks to improve the waste disposal charging system. Another example is Lu et al. compared the CWM performances between private and public sectors using the big data in 2011 and 2012, totally more than two million construction waste disposal records of about 4,000 construction projects conducted in Hong Kong, and found there is a notable disparity of construction waste management (CWM) performance between the public and private sectors [25]. This also provides references for government and sectors to improve their strategies in CWM. The use of big data generated from the platform can also be predicting the future waste generation. Chen et al. developed a universal S-curve for predicting the waste generation of new projects based on the waste disposal records in 2011, 2012, 2013 and 2014 [26]. The S-curve equation of a new project in Hong Kong can be expressed by inputting the characteristics, including contract sum, location, public and private nature of the project. This makes waste management plan easier and more accurate.

\section{Conclusion}

This study proposed a framework of developing a big data platform in CWM in Hong Kong by considering the CWM roadmap, data collection, and data storage and analysis. The framework of the platform can provide government and industry with a better understanding of their performance in CWM so as to achieve sustained improvement. Since different regions may have different roadmaps for CWM, the framework is only applicable to those regions whose construction waste is systematically managed by government. The study then examined the availability of the platform by referring to the previous examples of using the existing big data. It is found that this platform will contribute to environmental protection and benefit a large group of stakeholders, including government, contractors, professionals and general publics. This study only listed some examples of benefits from the platform. Future studies are suggested to figure out more value that can be discovered from the big data platform, so as to demonstrate the importance of adopting such a platform in CWM.

\section{References}

[1]U.S. EPA (1998). Characteristics of building-related construction and demolition debris in the United States. U.S. Environmental Protection Agency. Report prepared by Franklin Associates, Rep. No. EPA 530-R-98-010.

[2]McGrath C., and Anderson M. (2000). Waste minimizing on a construction site. Building Research Establishment Digest, 447. 
[3] Lingard, H., Gilbert, G., and Graham P. (2001). Improving solid waste reduction and recycling performance using goal setting and feedback, Construct Management Economics, 19 (8) (2001), 809-817

[4]HKEPD (2015). https://www.wastereduction.gov.hk/sites/default/files/msw2013.pdf, accessed on $11 / 06 / 2015$.

[5]HKEPD (2015).

http://www.epd.gov.hk/epd/english/environmentinhk/waste/waste_maincontent.html, accessed on 09/09/2015.

[6]Poon, C. S., Ann, T. W., and Ng, L. H. (2001). On-site sorting of construction and demolition waste in Hong Kong. Resources, conservation and recycling, 32(2), 157-172.

[7]Wang, J., Yuan, H., Kang, X., and Lu, W. (2010). Critical success factors for on-site sorting of construction waste: a China study. Resources, conservation and recycling, 54(11), 931-936.

[8]Jaillon, L., Poon, C.S., and Chiang, Y.H. (2009). Quantifying the waste reduction potential of using prefabrication in building construction in Hong Kong. Waste Management, 29(1), 309-320.

[9]Lu, W.S., and Yuan, H.P. (2013). Investigating waste reduction potential in the upstream processes of offshore prefabrication construction. Renewable and Sustainable Energy Reviews. 28, 804-811.

[10]Tam, V.W., and Hao, J.J. (2014). Prefabrication as a mean of minimizing construction waste on site. International Journal of Construction Management, 14(2), 113-121.

[11]Kourmpanis, B., Papadopoulos, A., Moustakas, K., Kourmoussis, F., Stylianou, M., and Loizidou, M. (2008). An integrated approach for the management of demolition waste in Cyprus. Waste Management \& Research, 26(6), 573-581.

[12]Poon, C.S., Yu, A.T.W., See, S.C., and Cheung, E. (2004). Minimizing demolition wastes in Hong Kong public housing projects. Construction Management and Economics, 22(8), 799-805.

[13]Mayer-Schönberger, V., and Cukier, K. (2013). Big data: A revolution that will transform how we live, work, and think. Houghton Mifflin Harcourt.

[14]Manyika, J., Chui, M., Brown, B., Bughin, J., and Dobbs, R., Roxburgh, C. and Byers, A.H. (2011). Big data: The next frontier for innovation, competition, and productivity. Report by McKinsey Global Institute.

[15]Gobble M.M. (2013). Big Data: The Next Big Thing in Innovation. Research-Technology Management, January-February.

[16]McAfee, A. and Brynjolfsson, E. (2012). Big data: the management revolution. Harvard business review, (90), 60-6.

[17]Murdoch, T.B. and Detsky, A.S. (2013). The inevitable application of big data to health care. Jama, 309(13), 1351-1352.

[18]Hampton, S.E., Strasser, C.A., Tewksbury, J.J., Gram, W.K., Budden, A.E., Batcheller, A.L., ... and Porter, J.H. (2013). Big data and the future of ecology. Frontiers in Ecology and the Environment, 11(3), 156-162.

[19]Chen, H., Chiang, R.H., and Storey, V.C. (2012). Business Intelligence and Analytics: From Big Data to Big Impact. MIS Quart, 36(4), 1165-1188.

[20]Lu, W., and Tam, V. W. (2013). Construction waste management policies and their effectiveness in Hong Kong: A longitudinal review. Renewable and Sustainable Energy Reviews, 23, 214-223.

[21]McCallum, A. (2005). Information extraction: Distilling structured data from unstructured text. Queue, 3(9), 48-57.

[22]HKEPD (2015). http://www.epd.gov.hk/epd/misc/cdm/scheme.htm, accessed on 09/09/2015

[23]Wu, Z., Shen, L., Ann, T. W., and Zhang, X. (2015). A comparative analysis of waste 
management requirements between five green building rating systems for new residential buildings. Journal of Cleaner Production.

[24]Chen, X., Lu, W., Ye, M., and Shen, L. (2015). Construction Waste Generation Rate (WGR) Revisited: A Big Data Approach. In Proceedings of the 19th International Symposium on Advancement of Construction Management and Real Estate (pp. 843-854). Springer Berlin Heidelberg.

[25]Lu, W., Chen, X., Ho, D. C., \& Wang, H. (2015). Analysis of the construction waste management performance in Hong Kong: the public and private sectors compared using big data. Journal of Cleaner Production.

[26]Chen, X., Lu, W., and Peng, Y. (2015). The S-curve for forecasting construction waste generation. In Proceedings of International Conference on Solid Waste. 12-23 May 2015, Hong Kong. 